\title{
Endoscopic Endonasal Transsphenoidal Approach to Pituitary Adenoma: A Multi-disciplinary Approach
}

Deepak Regmi, ${ }^{1}$ Amit Thapa, ${ }^{2}$ Bidur KC, ${ }^{2}$ Bikram Shakya ${ }^{2}$

1'Department of ENT- Head and Neck Surgery, Kathmandu Medical College, Sinamangal Kathmandu, Nepal, ${ }^{2}$ Department of Neurological Surgery, Kathmandu Medical College, Sinamangal Kathmandu, Nepal.

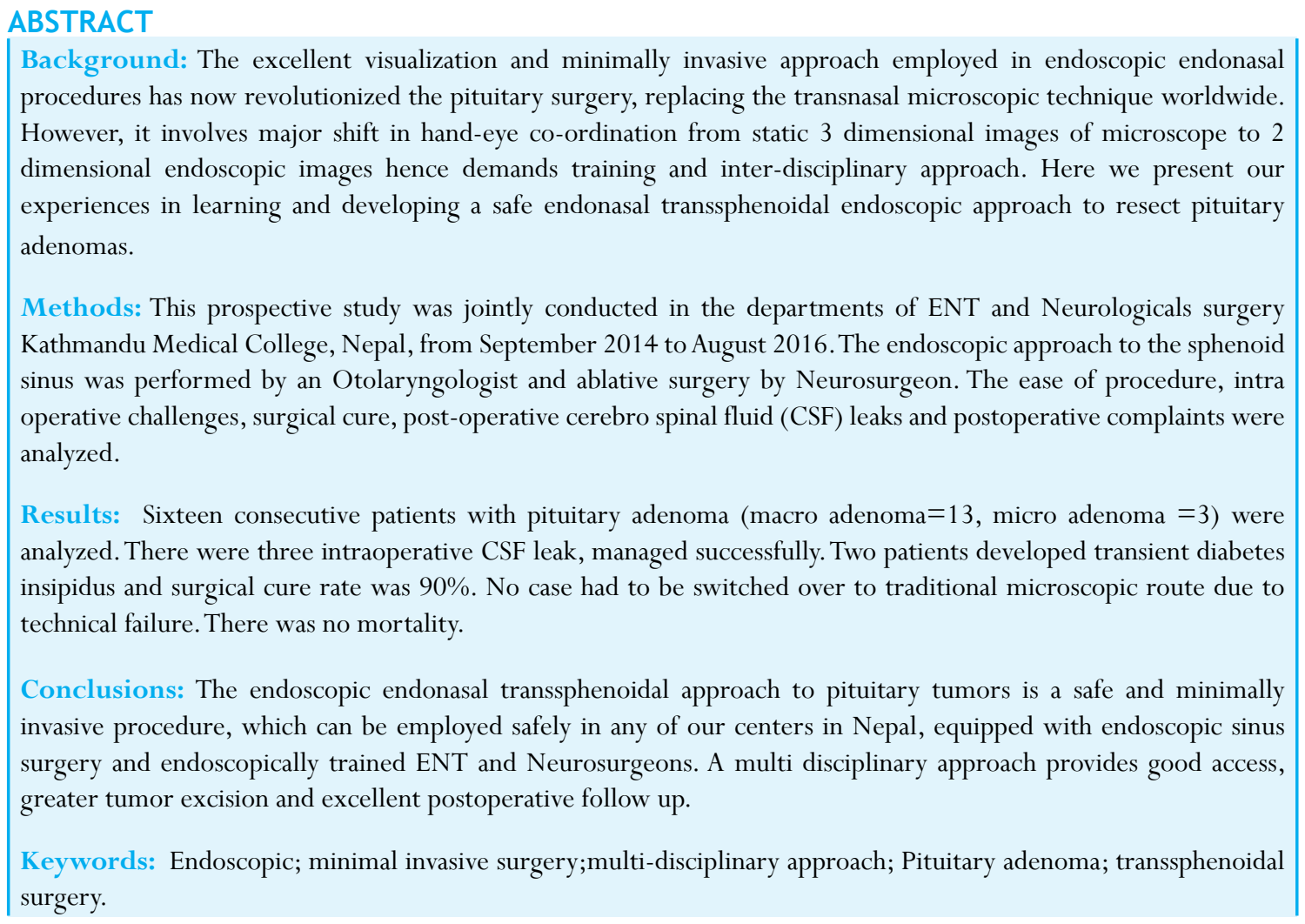

\section{INTRODUCTION}

The mainstay of treatment of pituitary adenoma is the surgery. Currently the direct endoscopic endonasal transsphenoidal approach has gained popularity. The main advantages of the endoscope over the operating microscope are that it gives a clearer angled close up panoramic view and allows more complete tumor removal as illumination is close to the target. However it involves endoscopic equipments as well as expertise in handling tissues in such closed corridors.

Our centre is a multi-speciality tertiary care hospital in Nepal where ENT department has all the necessary equipment for endoscopic surgery. Neurosurgeons perform pituitary surgeries conventionally by transnasal microscopic approach. Minimal invasive surgery is devel- oping leaps and bounds universally and Nepal is also not left untouched. We like-minded ENT and Neurosurgeons designed this study to assess whether endoscopic endonasal pituitary surgery is safe and feasible in our setup and to study the benefits of a multi disciplinary approach.

\section{METHODS}

This prospective study was jointly conducted in the departments of ENT and Neurosurgery, Kathmandu Medical College Teaching Hospital, Kathmandu, Nepal from September 2014 to August 2016. All the consecutive patients who were diagnosed with pituitary adenoma and gave written informed consent for endoscopic endonasal trans-sphenoidal surgery were enrolled in the study. The ethical clearance was taken from the institutional 
review committee before the commencement of study. The patients' demographic data, ease of the procedure and intraoperative challenges, duration of the operation, postoperative CSF leak or other complications and surgical cure rate were analyzed. Minimum follow-up period was one year.

All the patients were diagnosed radiologically with 3 Tesla magnetic resonance imaging (MRI) before and after Gadolinium based contrast medium. On the basis of maximum tumor dimension, it was classified as macroadenoma $(>10 \mathrm{~mm})$ and microadenoma $(<10 \mathrm{~mm})$. Lesions were also classified as pure sellar, suprasellar or parasellar. Nose and paranasal sinus CT scan was obtained in each case to assess the paranasal and septal anatomy as a roadmap for surgical planning in initial 10 cases. Later due to financial restraints and availability of thin coronal sections of sella on MRI, CT was not performed on patients.

Under general anesthesia, the patients were placed in supine position with head extended at $30^{\circ}$ angle to the shoulder and rotated towards left side, fixed on Mayo Head holder 3-pins fixator device. Lumbar drain was kept in anticipated CSF leak cases only. After applying nasal decongestant, the ENT surgeon started the operation from right side of the nostril. A $18 \mathrm{~mm}$ long $0^{\circ}$ rigid nasal endoscope was used to perform diagnostic nasal endoscopy and introduced via the paraseptal route, medial to middle turbinate to localize the sphenoid sinus ostium which was located about $1-1.5 \mathrm{~cm}$ above the choana. The middle turbinate was never sacrificed. A Hadad or rescue flap was elevated only in selected cases of macroadenoma with suprasellar or parasellar extension with high chance of CSF leak. This was done to preserve the posterior nasoseptal artery from accidental injury during widening of the sphenoid ostium inferiorly. The sphenoid sinus widening was started with kerrison punch inferiorly and then horizontally towards the opposite side across the back of the septum. During this, the septum was dislocated from the anterior wall of the rostrum and opposite side sphenoid sinus was approached. The intersphenoid septum was removed and anterior sellar wall viewed and the overlying mucosa was removed. The landmarks for good exposure of the sella were tuberculum sella superiorly, the bulge of the optic nerves at 10 and 2 o'clock, cavernous sinuses at 3 and 9 o'clock, carotid bulge at 5 and 7 o'clock and the clivus inferiorly. ${ }^{1}$ After the access is created, Neurosurgeons would take over the rest of the procedure with the ENT surgeon assistance with guiding the endoscope. After opening the sellar floor, the dura was incised using B.P. 15 knife in a ' $\mathrm{H}$ pattern' fashion. Then the tumor was curetted and specimen sent for histopathology. During this, the lateral and inferior tumor was removed first to prevent prolapse of the diaphragm sella which might block the view laterally and posteriorly and made remaining tumor removal very difficult. Then the $30^{\circ}$ angled endoscope was employed to inspect the suprasellar and parasellar region to ensure complete tumor removal. After tumor removal, sellar cavity was packed with surgicel for haemostasis and laid over with fat graft. If intra operative CSF leak was present, repair was done using fascia lata supported by fat graft inside the sella and anterior wall of the sella was reconstructed by bone from anterior sphenoid wall or the septum which was covered with another layer of fascia and tissue glue. Finally, it was coved by nasoseptal flap and merocel uni nostril nasal packing was done for 48 hours. All the operations were done by the first two authors.

\section{RESULTS}

A total of 16 patients underwent endoscopic endonasal procedures for pituitary adenoma by two surgeons, binostril, four hand technique. There were seven males and nine females. Age ranged from 18-65 years (mean 51 years). Thirteen patients had pituitary macroadenoma (of which 2 were prolactinomas) and 3 had microadenoma (all Cushing Disease). Four cases of pituitary macroadenoma had suprasellar and parasellar extension where intraoperative complications like CSF leak and bleeding were anticipated, hence a lumbar drain was kept and rescue nasoseptal (Hadad) flap of appropriate size was elevated at the beginning of nasal part of the surgery. Intraoperative complications encountered were very minimal such as more bleeding, frequent fogging of the endoscope and CSF leak (3 cases) and transient diabetes insipidus in two cases. One case had to be reexplored in immediate post operative period due to nasal mucosal bleeding and it was controlled. None of the cases had to be abandoned and switched over to microscopic approach due to technical failure. Mean operative time was 185 minutes, with access taking an average of 45 minutes more than conventional technique of sublabial trans-septal approach. Hadad reconstruction was employed in four cases where the post operative merocele nasal packing was done for 48 hours. Post operative nasal packing was avoided in rest of the cases. There was no mortality. Mean hospital stay was 5 days (3-7 days). Follow up for an average of 1 year in all patients showed minor crusting and patients did not complain of major nasal airway problems. The surgical success rate was measured on the basis of post operative MRI scan and hormonal status. For both functional and non functional pituitary tumors, it was $90 \%$. 
We identified 2 stages of learning curve, first involved with hand eye co-ordination, maintaining clarity of visual field and achieving wider exposure with the later involved in maintaining hemostasis induced by cavernous sinus exploration and CSF leak by playing around invasive tumors.

\section{DISCUSSION}

Pituitary adenomas constitute $10 \%$ of all intracranial neoplasms. ${ }^{2}$ The mainstay of treatment of pituitary adenoma is the surgery. Pituitary microadenomas are the intrasellar adenomas of less than $1 \mathrm{~cm}$ in diameter without sellar enlargement where as pituitary macroadenomas are those larger than $1 \mathrm{~cm}$ in diameter with generalized sellar enlargement and it may cause symptoms of mass effects like headache, visual impairment or hormonal abnormalities. ${ }^{3}$

The earliest transsphenoidal surgeries (1907-1909) were done via the external rhinotomy incisions introduced by Schloffer, von Eiselsberg and Kocher. ${ }^{4}$ Later on sublabialtransseptal, endonasal transseptal and transcolumellar approaches came into play but all inherited the complications like numbness of lip and teeth, septal perforation, crusts formation etc. The primary obstacle to the sella remained illumination and visualization of the operative field till 1960s, when Hardy popularized direct transsphenoidal approach with the use of operating microscope. Its excellent illumination and magnification enabled effective removal of the pituitary tumors without significant anatomical disruption. The rigid endoscopes used for sinus surgery provided the inspiration for their use in pituitary surgery. ${ }^{5}$ Jankowski (1992) was the first to provide first description of fully endoscopic transnasal technique which was popularized by Jho et al. ${ }^{6,7}$

The transsphenoidal midline approach has become the standard access to the pituitary and endoscope represents one of the latest technical innovation which allows wider panoramic view. Endoscopic endonasal surgery, which inherits unlimited potential, provides a new choice for pituitary adenoma. ${ }^{8}$ There are many literatures in the favour of this technique which ensures superior visualization, magnification, more complete tumor removal and decreased complication rate to that of conventional microscopic technique, thus suggesting it to be a minimally invasive procedure as the nasal and septal architecture is maximally preserved. ${ }^{6}$, 8,9 The key principle in understanding and successfully achieving good results with these procedure is the close collaboration between the otolaryngologist with good experience in functional endoscopic sinus surgery and the neurosurgeon experienced in transsphenoidal pituitary surgery. ${ }^{10}$ The advantage of having a team is the ENT surgeon's familiarity with the route and technique and ability to handle minor complaints of nasal bleed and out patient nasal endoscopy to inspect the post operative wounds. Neurosurgeons have ability to handle neural tumors and handle cavernous sinus. Such collaboration has decreased the rate of complications and morbidity ${ }^{4}$ and in our scenario had worked for cost efficient way of post operative follow ups.

The complication rate of previously published endoscopic studies range from $10 \%$ to $26.3 \%$ and mortality rate of $0 \%$ to $0.68 \% \cdot{ }^{6,10-13}$ The complications and mortality rate of microscopic transsphenoidal approach are $8.2 \%$ to $47 \%$ and $0 \%$ to $0.9 \%$ respectively. ${ }^{14,15}$ The observed rate of complications in the present study are comparable to previous studies. The possible explanation behind the lower complications rate in the endoscopic technique are due to better visualization, less bone and mucosal dissection and the team work.

Intraoperative or postoperative CSF leak is the most frequent complication of endoscopic endonasal procedures of the sella. We encountered three CSF leaks intraoperatively during excision of large macroadenoma. All the cases were managed successfully with fat, fascia, bone and nasoseptal (Hadad) flap. Lumbar drain was kept in all in addition to bed rest. We encountered more CSF leaks $(18.75 \%)$ than previously reported endoscopic series $(1.2 \% \text { to } 6 \%)^{6,12,13}$. This might be because we were little aggressive while dealing with the extensive tumors involving the suprasellar region that too in early phase of the surgery. The learning curve was steep.

The reported incidence of Diabetes Insipidus (DI) in the endoscopic pituitary sugery ranges from $2.5-20 \% .^{13,16} \mathrm{It}$ may be transient or permanent. The DI we encountered in our series were comparable to other series and all were temporary. This might be due to the simple manipulation of the pituitary gland during surgery. Temporary $\mathrm{DI}$ is assumed to be caused by temporary dysfunction of the vasopressin producing neurons due to surgical trauma. ${ }^{14}$

Zada et al. ${ }^{17}$ has identified few causes for conversion to microscopic or endoscopic assisted approach. They are reoperations with scarring along with losss of anatomical landmark especially in Cushing's disease and acromegaly, atypical nasal or sphenoidal anatomy, desire for binocular vision, major bleeding etc. We did not have to convert any of the cases to the microscopic technique due to any of the technical failures. 


\section{CONCLUSIONS}

The endoscopic endonasal transsphenoidal approach to pituitary adenoma is a safe and minimally invasive procedure. This technique can be employed safely in a center equipped with endoscopic sinus surgery with trained surgeons to handle endoscope. When likeminded health professionals who believe on teamwork and recognize each other's expertise are integrated, the patients will get maximum benefit. Due to the thorough knowledge of endoscopic anatomy of nose and paranasal sinus, an ENT surgeon can guide the Neurosurgeon till the sphenoidal phase of the surgery. Then he can assist to utilize the endoscope at its best providing a wide angled, magnified and panaromic perspect of the sella to his neurosurgeon colleague for maximum tumor excision. At our hospitals, the endoscope has replaced the operating microscope for surgery of pituitary adenomas.

\section{REFERENCES}

1. Jho HD, Alfieri A. Endoscopic endonasal pituitary surgery: evolution of surgical technique and equipment in 150 operations. Minim Invas Neurosurg. 2001;44:1-12. [Link]

2. Ezzat S, Asa SL, Couldwell WT, Barr CE, Dodge WE, Vance ML et al. The prevalence of pituitary adenomas: a systematic review. Cancer 2004; 101(3): 613-19. [Link]

3. Saad MSM, Gendeh BS, Husain S. Endonasal endoscopic transsphenoidal pituitary surgery for pituitary adenoma: a retrospective analysis of surgical outcome. Med. J Malaysia. 2011; 66(5): 443-6[PubMed]

4. Jane JA Jr, Han J, Prevedello DM, Jagannathan J, Dumont AS, Laws ER Jr. Perspectives on endoscopic transsphenoidal surgery. Neuro- surg Focus 2005;19(6):E2 [Link]

5. Varsgney S, Gupta C, Bansal KK, Bist SS, Bhagat S. Endoscopic trans-nasal trans-sphenoidal (TNTS) approach for pituitary adenomas: our experience. Indian J Otolaryngol Head Neck Surg. 2013;65(2):308-13[Link]

6. Jankowski R, Auque J, Simon C, Marchal JC, Hepner H, Wayoff M. Endoscopic pituitary tumor surgery. Laryngoscope. 1992; 102(198-20):2[Full Text]

7. Shou X, Shen M, Zhang Q, Zhang Y, He W, Zengyi Ma, et al. Endoscopic endonasal pituitary adenomas surgery: the surgical experience of 178 consecutive patients and learning curve of two neurosurgeons. BMC Neurol. 2016; 16: 247. [BMC]
8. Rivera-Serrano CM, Snyderman $\mathrm{CH}$, Gardner P, Prevedello D, Wheless S, Kassam AB, et al. Nasoseptal "rescue" flap: a novel modification of the nasoseptal flap technique for pituitary surgery. Laryngoscope. 2011;121990-3.[FullText]

9. Hadad G, Bassagasteguy L, Carrau RL, Mataza JC, Kassam A, Snyderman $\mathrm{CH}$, et al. A novel reconstructive technique following endoscopic expanded endonasal approaches: vascular pedicle nasoseptal flap. Laryngoscope. 2006;116:1881-5. [Link]

10. Chone CT, Sampaio MH, Sakano E, Paschoal JR, Garnes HM, Queiroz L, etal.Endoscopic endonasal transsphenoidal resection of pituitary adenomas: preliminary evaluation of consecutive cases. Braz J Otorhinolaryngol. 2014;80:14651. [ScienceDirect]

11. Frank G, Pasquini E, Farneti G, Mazzatenta D, Sciarretta V,- Grasso V, et al. The endoscopic versus the traditional approach in pituitary surgery. Neuroendocrinology. 2006;83:240-8. [FullText]

12. Cappabianca P, Cavallo LM, Colao A, deDivitiis E. Surgical complications associated with the endoscopic endonasaltranss- phenoidal approach for pituitary adenomas. J Neurosurg. 2002;97:293-8.[PubMed]

13. Dehdashti AR, Ganna A, Karabatsou K, Gentili F. Pure endosco- pic endonasal approach for pituitary adenomas: early surgical results in 200 patients and comparison with previous microsurgical series. Neurosurgery. 2008;62:1006-15. [Link]

14. semple PL, Laws ER Jr. Complications in a contemporary series of patients who underwent transsphenoidal surgery for Cushing's disease. J Neurosurg. 1999;91:175-9. [Link]

15. Gondim JA, Schops M, de Almeida JP, Albuquerque LAF, Gomes E, Ferraz T, et al. Endoscopic endonasal transphenoidal surgery: surgical results of 228 pituitary adenomas treated in a pituitary center. Pituitary. 2010;13:68-77. [Link]

16. Tabaee A, Anand VK, Barrón Y, Hiltzik DH, Brown SM, Kacker A, et al. Endoscopic pituitary surgery: a systematic review and meta-analysis. J Neurosurg. 2009;111:54554. [Link]

17. Zada G, Agarwalla PK, Mukundan S, Jr, Dunn I, Golby AJ, Laws ER.,Jr The neurosurgical anatomy of the sphenoid sinus and sellar floor in endoscopic transsphenoidal surgery. J Neurosurg. 2011;114:1319-30.[Link] 